\title{
LA EFICACIA DEL CONTROL DIFUSO EN LA CONSTITUCIÓN MEXICANA PARA SALVAGUARDAR LOS DERECHOS HUMANOS
}

José Guillermo FAJARDO MONTOYA ${ }^{1}$

RESUMEN: El presente trabajo tiene como propósito determinar si a partir de que en México se reconoció la facultad que tienen los órganos jurisdiccionales de analizar si mediante el control difuso una norma se encuentra en contravención a la Constitución o tratados internacionales, dicho instrumento se puede considerar como un medio eficaz de control constitucional para salvaguardar los derechos humanos.

Palabras clave: Control Difuso, Convencionalidad, Constitución, Eficacia, Derechos Humanos.

ABSTRACT: The purpose of this article is to determine whether, since Mexico has recognized the power of the jurisdictional bodies to analyze whether through a diffused control a rule is in violation of the Constitution or international treaties, this instrument can be considered an effective means of constitutional control to safeguard human rights.

Keywords: Diffuse Control, Conventionality, Constitution, Effectiveness, Human Rights.

SUMARIO: I. Introducción; II. Antecedentes del control difuso; III. Postura histórica de la Suprema Corte de Justicia de la Nación respecto al control difuso; IV. Postura actual de la Suprema Corte de Justicia de la Nación con relación al control difuso; V. El control difuso hoy; VI. Presupuestos para ejercer el control difuso; VII. Conclusiones; VIII. Bibliografía

1 Secretario del Primer Tribunal Colegiado en Materia de Trabajo del Decimoctavo Circuito. 


\section{InTRODUCCIÓN}

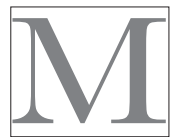

ucho se habla de las reformas a la Constitución de 2011 que derivaron en el reconocimiento de derechos humanos, lo cual trajo consigo una reforma progresista en nuestro marco jurídico en relación con la implementación del control difuso a cargo de todas las autoridades jurisdiccionales para poder ejercerlo e inaplicar alguna ley o norma que se encuentre en contravención a la Constitución o tratados internacionales, sin embargo, después de 7 años de la mencionada reforma no podemos asegurar que dicho control se lleve a cabo con regularidad por todo órgano jurisdiccional del país, no obstante, este estudio tiene como propósito determinar si a partir de que en México se reconoció a los órganos jurisdiccionales la facultad para ejercer el control difuso de constitucionalidad, éste es un medio eficaz de control constitucional para salvaguardar los derechos humanos.

\section{Antecedentes del control difuso}

El control difuso surge en el derecho anglo-americano a partir de la sentencia que dictó John Marshall el 24 de febrero de 1803 en el caso Marbury vs Madison y en diversos números de "el Federalista" -en específico los artículos del 78 al 82 de Hamilton-, figura que consiste en el poder que se otorga a todos los jueces para inaplicar las leyes cuando no sean acordes a la constitución. ${ }^{2}$

No obstante, el control difuso en sede doméstica o control interno de convencionalidad se planteó como tal en los tribunales europeos, en el caso Administration des finances italiennes vs Simmenthal el 9 de marzo de 1978 por el Tribunal de Justicia de las Comunidades

2 Márquez Martínez, Laura, Control difuso desde una perspectiva de derecho de acceso a la justicia, México, Suprema Corte de Justicia de la Nación, comisión organizadora del poder judicial para los festejos del centenario de la Constitución Política de los Estados Unidos Mexicanos, 2017, p. 18. 
Europeas. En dicha resolución, la Corte Europea atribuyó de modo difuso a los jueces nacionales la condición de jueces de derecho común del derecho comunitario y precisó que el control por el que cabe dar supremacía al derecho comunitario sobre el local no debe quedar en manos exclusivamente de las cortes constitucionales de los estados, sin que:

[...] El Juez nacional encargado de aplicar, en el marco de su competencia, las disposiciones del Derecho comunitario, está obligado a garantizar la plena eficacia de dichas normas declarando, si procede, inaplicarlas, por su propia iniciativa, cualesquiera disposiciones contrarias a la legislación nacional, aunque sean posteriores, sin que esté obligado a solicitar o a esperar la derogación previa de éstas por vía legislativa o por cualquier otro procedimiento constitucional. ${ }^{3}$

Por otro lado, la Corte Interamericana de Derechos Humanos ha adoptado diversos criterios jurisprudenciales mediante los cuales ha determinado que los jueces nacionales se encuentran obligados a inaplicar las normas contrarias a la Convención Americana, de los cuales, dos han sido el pilar de tal idea; la primera, en el caso $\mathrm{Al}$ monacid Arellano vs Chile, en la que declaró la existencia de un efecto represivo o destructivo de la aplicación de la Convención Americana a la legislación nacional, lo cual se traduce en la inaplicación de la norma que sea contraria a la Convención. La segunda se dio en el caso Radilla Pacheco vs México, en la cual resolvió que los jueces no sólo deben dejar de aplicar normas contrarias a la Convención Americana, sino que también deben de aplicar y hacer funcionar ese tratado internacional y la jurisprudencia de la Corte Interamericana para armonizar las normas nacionales e internacionales. ${ }^{4}$

3 Rojas Caballero, Ariel Alberto, El control difuso y la recepción del control de convencionalidad en materia de derechos humanos en México, México, Porrúa, 2015, p. 86.

4 Angulo Jacobo, Luis Fernando, "El control difuso de convencionalidad en México", Revista del Instituto de la Judicatura Federal, México, 2013, Núm. 35, enero, p. 76, <https://www.ijf.cjf.gob.mx/Sitio2016/include/sections /revista/ rev35_C.html>, consultada el 23 de mayo de 2018. 
Asimismo, la Corte Interamericana de Derechos Humanos ha manifestado que es al Poder Judicial de cada estado miembro a quien corresponde realizar el control difuso de la convencionalidad, lo que ha implicado que aquéllos países en donde el control de convencionalidad se encontraba concentrado en un número limitado de órganos jurisdiccionales hayan tenido que adaptar su ordenamiento legal a efecto de extender dicha facultad para que la puedan ejercer más operadores jurídicos.

\section{Antecedentes del control difuso en México}

El control constitucional difuso no es un tema novedoso en el estudio del derecho constitucional en México, ya que si bien es verdad que la Constitución de 1824 no precisó nada al respecto, la de 1857 sí lo contempló en su artículo 126, que aunque no fue incluido en el proyecto original enviado por Venustiano Carranza al Congreso Constituyente, con posterioridad se incorporó por la Comisión de la Constitución, para que se aprobara y se incorporara su texto en el artículo 133 de la vigente Constitución de 1917 que prevé la supremacía constitucional de las leyes emanadas de ella y de los tratados internacionales suscritos por el ejecutivo federal y ratificados por el Senado. ${ }^{5}$

En ese precepto constitucional se previó desde su inicio el ejercicio del control constitucional difuso a favor de los jueces nacionales -locales o federales- y los autorizó para que observaran la

5 Samaniego Santamaría, Luis Gerardo, "Control Difuso de constitucionalidadconvencionalidad. Evolución jurisprudencial a cien años de la constitución mexicana de 1917", en Ferrer Mac-Gregor, Eduardo y Flores Panoja, Rogelio (coord.), La constitución y sus garantías. A 100 años de la Constitución de Querétaro de 1917. Memoria del XI encuentro Iberoamericano y VIII congreso mexicano de derecho procesal constitucional, México, UNAM, Instituto de Investigaciones Jurídicas, Instituto de Estudios Constitucionales de Querétaro, 2017, p. 867-868, <https://archivos. juridi cas.unam.mx/www/bjv/libros/10/4633/38.pdf>, consultado el 23 de mayo 2018, consultada el 23 de mayo de 2018. 
Constitución Federal, leyes y tratados a pesar de las disposiciones en contrario que pudieran haber en las leyes y constituciones de los estados, ${ }^{6}$ es decir, de este artículo constitucional emanó la facultad de ejercer el control difuso de constitucionalidad en México.

A partir de que entró en vigor la Constitución de 1917, dicho precepto constitucional sólo ha tenido dos reformas, la primera el 18 de enero de $1934,{ }^{7}$ en el sentido de que los tratados internacionales para ser ley suprema debían estar conforme a la Constitución y que aquellos celebrados por el Presidente de la República tenían que ser ratificados, ya no por el Congreso sino sólo por la Cámara de Senadores $;^{8}$ en la segunda que tuvo lugar el 29 de enero de $2016,{ }^{9}$ sólo se sustituyó la frase "Los jueces de cada Estado" para quedar "Los jueces de cada entidad federativa"; reforma que se puede entender se realizó, para delimitar quiénes, en el estado mexicano, pueden ejercer ese control, es decir, la forma en que estaba redactado antes de la reforma mencionada, generaba una interpretación en sentido amplio, porque del mismo texto se advertía que no sólo los jueces mexicanos podían hacer uso de esa facultad, sino también cualquier juzgador de otro Estado, es decir, de otro país, al extender dicha facultad "al juez de cada Estado" sin delimitar o señalar al estado mexicano; de ahí que se pueda entender que la reforma limitó el ejercicio del control difuso a favor de los operadores locales o federales de cada estado que pertenezca a la federación, es decir al estado mexicano y sólo ellos, como se precisó en el texto constitucional, pueden ejercer el control difuso.

\section{Idem.}

7 Diario Oficial de la Federación, 18 de enero de 1934, pp. 206-208, $<$ http://www.dof.gob.mx/nota_to_imagen_fs.php?cod_diario=191181\& pagina $=3 \&$ seccion $=0>$, consultada el 23 de mayo de 2018 .

8 Samaniego Santamaría, Luis Gerardo, op. cit. p. 869.

9 Diario Oficial de la Federación, 29 de enero de 2016, p. 25, < http: / / www.dof. gob.mx/nota_to_imagen_fs.php?cod_diario=268141 \&pagina $=25 \&$ seccion $=0>$, consultada el 23 de mayo de 2018. 


\section{ili. Postura histórica de la Suprema Corte de Justicia DE la Nación Respecto al CONTROL difuso}

En relación con la interpretación del artículo 133 constitucional y en específico al control difuso en México, la Suprema Corte de Justicia de la Nación históricamente ha interpretado esa disposición respecto de qué órganos pueden ejercerlo y la forma en que se debe llevar a cabo su estudio.

En 1926 sostuvo en la tesis "CONSTITUCión FEDERAL", ${ }^{\circ}$ que el control difuso de constitucionalidad lo debían ejercer todos los jueces, tanto federales como estatales, arreglándose siempre a la Constitución Federal, leyes del Congreso de la Unión y los tratados a pesar de las disposiciones en contrario que pudiera haber en las constituciones o leyes de los estados, criterio que armonizó lo dispuesto en la norma constitucional con lo resuelto por el Poder Judicial de la Federación.

Posteriormente, mediante el criterio aislado "LEYES, FACULTAD DE LAS AUTORIDADES PARA DEGLARARLAS ANTICONSTITUGIONALES" la Corte sostuvo que con relación a disposiciones manifiestamente contrarias a la Constitución Federal, las autoridades comunes debían abstenerse de aplicarlas, sin que ello significara que tratándose de un precepto de ley, que no estuviera en contradicción manifiesta con algun precepto de la Constitución, y cuya inconstitucionalidad sólo pudiera sostenerse con razonamientos que no pudieron derivarse de una manera clara y precisa de la misma ley, pudiera una autoridad del fuero común declarar su inconstitucionalidad, pues no estaba facultada para hacer semejante declaración, en virtud de que dicha facultad sólo la tenía la Suprema Corte o los Jueces de Distrito. ${ }^{11}$

10 Tesis, Semanario Judicial de la Federación, Quinta Época, t. XIX, julio de 1926, p. 117.

11 Tesis, Semanario Judicial de la Federación, Quinta Época, t. XLVI, noviembre de 1935, p. 2966. 
Asimismo, en 1942 ese órgano superior al resolver el amparo en revisión 1908/41, emitió la tesis "CONSTITUCIONALIDAD DE LAS LEYES, COMPETENCIA DEL TRIBUNAL FISGAL PARA EXAMINARLA Y ESTATUIR SOBRE ELLAS", mediante la cual estableció que las Salas del otrora Tribunal Fiscal de la Federación podían, al resolver sobre cuestiones de su competencia, decidir, conforme al artículo 133 de la Carta Magna, si la ley que apoyaba los actos impugnados era o no constitucional. ${ }^{12}$

Luego matizó su postura en la tesis "CONSTITUCiÓN. SU APLICACIÓN POR PARTE DE LAS AUTORIDADES DEL FUERO COMÚN GUANDO SE ENCUENTRA CONTRAVENIDA POR UNA LEY ORDINARIA", en relación con la aplicación del control difuso por las autoridades judiciales del fuero común en el sentido de que si bien estas últimas no pueden hacer una declaración de inconstitucionalidad de la ley, sí se encontraban obligadas a aplicar la Constitución Federal cuando el precepto de la ley ordinaria contraviniera directamente y de modo manifiesto, una disposición expresa del pacto federal, ${ }^{13}$ con lo cual pasó de una apertura plena a una limitada de interpretación de la Constitución. ${ }^{14}$

Dicha tendencia de limitación continuó y en 1968, la Suprema Corte emitió el criterio que lleva por rubro "CONSTITUGiONALIDAD DE LAS LEYES, EXAMEN DE LA, IMPROGEDENTE, POR LA AUTORIDAD JUDicial COMún", en este delimitó que sólo a los órganos del Poder Judicial de la Federación correspondía realizar declaratorias de inconstitucionalidad, pues sostuvo que no existía jurisprudencia que

12 Tesis, Semanario Judicial de la Federación, Quinta Época, t. LXXII, abril de 1942, p. 2570.

13 Tesis, Semanario Judicial de la Federación, Sexta Época, volumen LX, cuarta parte, febrero de 1960, p. 177.

14 Becerra Ramírez, José de Jesús, "El camino hacia el control difuso de constitucionalidad en México: la convencionalidad", Revista el Cotidiano, México, 2013, Núm. 180, julio-agosto, 2013, p. 12, <http://www.elcotidia noenlinea.com. mx/pdf/18003.pdf>, consultada el 23 de mayo de 2018. 
impusiera a la autoridad judicial del orden común, la aplicación del artículo 133 constitucional, pues no obstante que se había llegado a sostener ocasionalmente que podían calificar la constitucionalidad de las leyes que norman el contenido de sus resoluciones, también lo era que la mayoría de los precedentes se habían orientado en el sentido de considerar que sólo el Poder Judicial de la Federación podía calificar la constitucionalidad de las leyes a través del juicio constitucional de amparo. ${ }^{15}$

Finalmente el Alto Tribunal del país estableció dos jurisprudencias, la primera: "CONTROL JUDICIAL DE LA CONSTITUCiÓN. ES ATRIBUGIÓN EXCLUSIVA DEL PODER JUDICIAL DE LA FEDERACIÓN"; ${ }^{16} \mathrm{y}$ la segunda: "CONTROL DIFUSO DE LA GONSTITUGIONALIDAD DE NORMAS GENERALES. NO LO AUTORIZA EL ARTíCULO 133 DE LA CONSTITUCIÓN"; ${ }^{17}$ con las cuales definió que el ejercicio del control difuso de la constitución era una facultad exclusiva de los órganos del Poder Judicial de la Federación - Juzgados de Distrito, Tribunales Colegiado de Circuito y Suprema Corte de Justicia de la Nación- pues bajo la interpretación del artículo 133 constitucional relacionado con diversos artículos constitucionales, el control de constitucionalidad correspondía a dichos órganos federales a través de su competencia en el juicio de amparo, controversias constitucionales y acciones de inconstitucionalidad. Postura que prevaleció hasta las reformas constitucionales de 2011.

Lo anterior pone en evidencia el cambio de criterios que tuvo la Suprema Corte de Justicia de la Nación hasta antes de la reforma de 2011 en relación a la interpretación del artículo 133 constitucional y quiénes eran los únicos órganos jurisdiccionales que podían ser los

15 Tesis, Semanario Judicial de la Federación, Sexta Época, volumen CXXXV, cuarta parte, septiembre de 1968, p. 37.

16 Tesis P./J. 73/99, Semanario Judicial de la Federación y su Gaceta, Novena Época, t. X, agosto de 1999, p. 18.

17 Tesis P./J. 74/99, Semanario Judicial de la Federación y su Gaceta, Novena Época, t. X, agosto de 1999, p. 5. 
interpretes de la constitución, y pasar de una postura de apertura hacia un control difuso de constitucionalidad cambió a una posición de ejercicio exclusivo por parte del Poder Judicial de la Federación, excluyendo a los jueces del fuero común. ${ }^{18}$

iv. Postura actual de la Suprema Corte de Justicia de La Nación con Relación al control difuso

La reforma a la Constitución Federal que se publicó en el Diario Oficial de la Federación el 10 de junio de 2011, tuvo como objeto elevar a rango constitucional los derechos humanos reconocidos en los tratados internacionales que México ha celebrado y ratificado, así como fortalecer los mecanismos para su protección.

Por virtud de la reforma en comento se creó un bloque de constitucionalidad, en el cual tanto las normas de la Constitución que contienen derechos humanos como las de los tratados internacionales sobre esa materia, tienen el mismo rango y, por tanto, no es posible solucionar conflictos, mediante reglas de interpretación que aludan a la jerarquía, ya que el referido conflicto será interno, es decir, únicamente en la propia Constitución. ${ }^{19}$

En ese contexto, en el artículo $1^{\circ}$, párrafo segundo, de la Constitución Federal se incorporó el principio pro persona, a través del cual las normas relativas a los derechos humanos deben interpretarse de conformidad con la Constitución y con los tratados internacionales de esa materia, favoreciendo en todo tiempo a las personas la protección más amplia. De esa manera, ante un conflicto de interpretaciones respecto de una norma, las autoridades están obli-

18 Becerra Ramírez, José de Jesús, op.cit., p. 13.

19 Guerrero Rodríguez, Marcelo, “Contradicción 293/2011. Inobservancia del principio pro persona", Revista del Instituto de la fudicatura Federal, México, 2014, Núm. 36, enero, p. 257, <https://www.ijf.cjf.gob.mx/publicaciones/revista/36/ Marcelo\%20Guerrero\%20Rodr\%C3\%ADguez .pdf $>$, consultada el 23 de mayo de 2018 . 
gadas a elegir aquella que otorgue un mayor beneficio al gobernado o, en su defecto, aquella que le genere un menor perjuicio. ${ }^{20}$

Asimismo, la Suprema Corte de Justicia de la Nación al ejercer su facultad de atracción y resolver el amparo directo 8/2012 sostuvo que, por virtud del principio pro persona, cuando un mismo derecho fundamental esté reconocido en las dos fuentes supremas del ordenamiento jurídico, a saber, la Constitución y los tratados internacionales, la elección de la norma que será aplicable -en materia de derechos humanos-, atenderá a criterios que favorezcan al individuo, de conformidad con lo dispuesto en el segundo párrafo del artículo $1^{\circ}$ constitucional. Consideraciones que dieron sustento a la jurisprudencia "PRINCIPIO PRO PERSONA. CRITERIO DE SELEGCIÓN DE LA NORMA DE DERECHO FUNDAMENTAL APLICABLE". ${ }^{21}$

En relación con lo anterior, en el párrafo tercero del artículo $1^{\circ}$ constitucional se dispuso que todas las autoridades, en el ámbito de sus competencias tienen la obligación de promover, respetar, proteger y garantizar los derechos humanos de conformidad con los principios de universalidad, interdependencia, indivisibilidad y progresividad, siendo obligación del Estado, prevenir, investigar, sancionar, y reparar las violaciones a los derechos humanos que establezca la ley. ${ }^{22}$

Así, a la luz de esta disposición, todas las autoridades están constreñidas al respeto irrestricto de los derechos humanos, por lo que no es un deber exclusivo del legislador o del juez constitucio-

20 Guerrero Rodríguez, Marcelo, "Limitación al Poder Judicial de la Federación del control de regularidad constitucional ex officio. Análisis del amparo directo en revisión 1046/2012", Letras Jurídicas, Revista Electrónica de Derecho del Centro Universitario de la Ciénega, México, 2018, Núm 26, marzo-septiembre, <http://letrasjurídicas.cuci.udg.mx/index.php/letrasjurídic as/issue/view/228/ show Toc $>$, consultda el 16 de noviembre de 2018 .

21 Tesis 1a./J. 107/2012 (10a.), Semanario Judicial de la Federación y su Gaceta, Décima Época, libro XIII, octubre de 2012, t. 2, p. 799.

22 Guerrero Rodríguez, Marcelo, "Limitación al Poder Judicial de la Federación...", cit., pendiente de publicación. 
nal, sino de todos los entes públicos, administrativos, legislativos o judiciales. $^{23}$

En este sentido, el Máximo Tribunal del País estableció la tesis "Derechos humanos. Obligaciones CONSTitucionales de LAS AUTORIDADES EN LA MATERIA", ${ }^{24}$ en la que fijó que el párrafo tercero del artículo $1^{\circ}$ constitucional conlleva a que las autoridades actúen atendiendo a todas las personas por igual, con una visión interdependiente, ya que el ejercicio de un derecho humano implica necesariamente que se respeten y protejan múltiples derechos vinculados, los cuales no podrán dividirse, lo cual debe hacerse de forma progresiva, es decir, sin llevar a cabo un retroceso en los medios establecidos para su ejercicio, tutela, reparación y efectividad.

$\mathrm{Al}$ respecto, el principio de progresividad establece que los derechos no pueden ser disminuidos, sino que se deben aumentar de manera gradual. Así, a la luz de dicho principio, las interpretaciones de las leyes deben hacerse tomando en consideración las realizadas anteriormente, buscando no disminuir las determinaciones hechas sobre el parámetro y la sustancia de los derechos interpretados. ${ }^{25}$

La eficacia del contenido del artículo $1^{\circ}$ constitucional se vio fortalecida en el terreno judicial con motivo de lo resuelto el 14 de julio de 2011 por la Suprema Corte de Justicia de la Nación en el expediente varios 912/2010, formado con motivo de la sentencia en la que condenó la Corte Interamericana de Derechos Humanos al Estado Mexicano, en el caso Radilla Pacheco vs México; en esa resolución se llevó a cabo nuevamente una interpretación del ar-

23 Rojas Caballero, Ariel Alberto, Los derechos humanos en México, México, Porrúa, 2012, p. 68.

24 Tesis 1a. XVIII/2012 (9a.), Semanario Judicial de la Federación y su Gaceta, Décima Época, libro IX, junio de 2012, t. 1, p. 257.

25 Mancilla Castro, Roberto Gustavo, "El principio de progresividad en el ordenamiento constitucional mexicano", Cuestiones Constitucionales. Revista Mexicana de Derecho Constitucional. México, UNAM, 2015, No. 33, julio-diciembre, pp. 8385, <https://revistas.juridicas.unam.mx/index.php/cuestiones-constitucionales/ article/view/6098/8039>, consultada el 23 de mayo de 2018. 
tículo 133 de la Constitución Federal que permitió que los jueces del orden común pudieran ejercer un control difuso respecto de las normas ordinarias.

En efecto, en el caso Radilla Pacheco, la Corte Interamericana de Derechos Humanos reiteró su jurisprudencia relativa a que si bien los jueces y tribunales internos están sujetos al imperio de la ley y obligados a aplicar las disposiciones vigentes en el ordenamiento jurídico, también están obligados a velar porque los efectos de las disposiciones de la Convención Americana sobre Derechos Humanos no se vean mermados por la aplicación de leyes contrarias a su objeto y fin, que desde un inicio carecen de efectos jurídicos, por lo que el Poder Judicial debe ejercer un control de convencionalidad ex officio entre las normas internas y la citada Convención, en el marco de sus respectivas competencias y de las regulaciones procesales correspondientes. ${ }^{26}$

En ese sentido, la Suprema Corte de Justicia de la Nación, sostuvo en el expediente varios 912/2010 el criterio "CONTROL DE CONVENGIONALIDAD EX OFFICIO EN UN MODELO DE GONTROL DIFUSO DE CONSTITUCiONALIDAD", ${ }^{27}$ con el cual definió que los jueces están obligados a preferir los derechos humanos contenidos en la Constitución y en los tratados internacionales, aun a pesar de las disposiciones en contrario establecidas en cualquier norma inferior, precisando, que si bien los jueces no pueden hacer una declaración general sobre la invalidez o expulsar del orden jurídico las normas que consideren contrarias a los derechos humanos contenidos en la Constitución y en los tratados, sí están obligados a dejar de aplicar estas normas

${ }^{26}$ Caso Radilla Pacheco vs. México, sentencia de 23 de noviembre de 2009, Excepciones, Preliminares, Fondo, Reparaciones y Costas, Corte Interamericana de Derechos Humanos, pp. 92-93, <http://www.ordenjuridico.gob.mx/JurInt/ STCIDHM4.pdf $>$, consultada el 23 de mayo de 2018.

27 Tesis P. LXVII/2011(9a.) de rubro: "COnTRol DE COnVEncionalidad EX

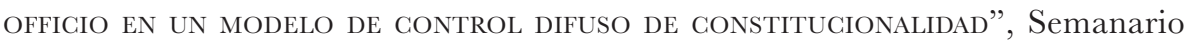
Judicial de la Federación y su Gaceta, Décima Época, Libro III, diciembre de 2011, tomo 1, página 535. 
inferiores dando preferencia a los contenidos en la Constitución y tratados que se relacionen con dicha materia.

Como consecuencia, el sistema de control jurisdiccional en México se reconfiguró. Por una parte, en un sistema concentrado en el cual, el Poder Judicial de la Federación, a través del juicio de amparo, las controversias constitucionales y las acciones de inconstitucionalidad, puede declarar la inconstitucionalidad de la norma con efectos generales o particulares de acuerdo al medio procesal de que se trate y, por otra parte, en un sistema difuso, que pueden ejercer todos los jueces del país -locales o federales- de manera incidental que puede dar como resultado la inaplicación de la norma impugnada. ${ }^{28}$

En concordancia con la reforma constitucional del 10 de junio de 2011, se modificó la Constitución Federal para consagrar al juicio de amparo como un medio de control constitucional eficaz para proteger y restituir a los gobernados en el goce de los derechos humanos reconocidos en la Constitución Federal.

Así, el artículo 103, fracción I de la Constitución Federal y el precepto $1^{\circ}$ de la Ley de Amparo establecen la procedencia del juicio en contra de normas generales, actos $\mathrm{u}$ omisiones de la autoridad que violen los derechos humanos reconocidos y las garantías otorgadas para su protección por la Constitución, así como por los tratados internacionales de los que el Estado Mexicano sea parte.

De tal manera, a la luz de las reformas en materia de amparo, los juzgadores que conozcan del juicio constitucional, tienen una obligación mayúscula de realizar una interpretación que observe los principios pro persona y progresividad y, en su caso, de inaplicar de

28 Acuña, Manuel, "El control difuso en México", en Ferrer Mac-Gregor, Eduardo (coord.), Derecho Procesal Constitucional Trasnacional. Interacción entre el derecho nacional y el derecho internacional, México, Porrúa, Instituto Mexicano de Derecho Procesal Constitucional, 2016, p. 117. 
oficio las normas que tiendan a transgredirlos, con independencia de que no fueran controvertidas de manera destacada. ${ }^{29}$

En ese sentido, el más Alto Tribunal del país ha establecido con claridad que el control concentrado que regía la actuación de los jueces mexicanos, ha quedado superado a efecto de dar paso al control difuso de la convencionalidad, con lo cual los jueces federales y locales están obligados a preferir los derechos humanos contenidos en la Constitución y en los tratados internacionales a pesar de las disposiciones en contrario establecidas en cualquier norma inferior.

Actualmente la Segunda Sala de la Suprema Corte de Justicia de la Nación determinó mediante criterio jurisprudencial que lleva por rubro "CONTROL DIFUSO. SU EJERGICIO EN EL JUICIO GONTENCIOSO ADMINISTRATIVO" 30 que conforme a lo dispuesto en los artículos $1^{\circ}$ y 133 constitucional, las autoridades jurisdiccionales ordinarias, para hacer respetar los derechos humanos establecidos en la propia Constitución y en los tratados internacionales de los que el Estado Mexicano sea parte, pueden inaplicar leyes secundarias, lo que constituye un control difuso de su constitucionalidad y convencionalidad, no obstante, aun subsiste el control concentrado de constitucionalidad y convencionalidad de leyes, cuya competencia corresponde en exclusiva al Poder Judicial de la Federación, a través del juicio de amparo, las controversias constitucionales y las acciones de inconstitucionalidad.

Esto es, si bien es verdad que los jueces no se encuentran expresamente autorizados para determinar la inconstitucionalidad de la norma y no pueden hacer una declaración general sobre la invalidez o expulsar del orden jurídico aquéllas que consideren contrarias a los derechos humanos contenidos en la Constitución y en los tratados internacionales - como sí sucede en las vías de control directas establecidas expresamente en los artículos 103, 107 y 105-

29 Idem.

30 Tesis 2a./J. 16/2014 (10a.), Gaceta del SemanarioJudicial de la Federación, Décima Época, libro 5, abril de 2014, t. I, p. 984. 
sí están obligados a dejar de aplicar las normas inferiores dando preferencia a los contenidos de la Constitución y de los tratados en esta materia. $^{31}$

\section{El CONTROL DIFUSO HOY}

Hoy podemos entender que existe un control difuso como medio preponderante que se debe ejercer por los operadores del derecho para verificar si las normas, actos o resoluciones que emitan las autoridades se encuentran acordes a los derechos humanos y garantías que establece la Constitución Política de los Estados Unidos Mexicanos y de no ser así, tiene como objeto inaplicar las normas que hayan servido de base a esos actos.

Este control constitucional conforme a la reforma de 2011, en relación con el artículo 133 de la Constitución Federal, es de carácter difuso, esto significa que todos los jueces -locales o federalesdeben interpretar y aplicar directamente las normas supremas y en su caso, inaplicar la norma que sea contraria a la Constitución cuando esta viole algún derecho humano, aun cuando los gobernados no lo soliciten, a lo cual hoy conocemos como control difuso de constitucionalidad ex officio.

En ese contexto, de una interpretación correcta de los artículos $1^{\circ}$ y 133 de la Constitución Federal, por virtud del control difuso de constitucionalidad (que comprende también las normas convencionales toda vez que forman parte de la Carta Magna) cualquier juzgador del país, sea del ámbito federal o local, puede inaplicar una norma al resolver un caso sometido a su jurisdicción cuando la estime violatoria de los derechos humanos contenidos en la Constitución Federal, aun cuando no pueda expulsarla del sistema normativo, en razón de que ello solo está reservado a medios de control constitucional de carácter concentrado, como son el juicio

31 Angulo Jacobo, Luis Fernando, "El control difuso de convencionalidad...", op.cit, p. 76 . 
de amparo indirecto, las controversias constitucionales y las acciones de inconstitucionalidad. ${ }^{32}$

En concordancia con lo expuesto y conforme a los criterios que ha emitido la Suprema Corte de Justicia de la Nación con relación a los artículos $1^{\circ}$ y 133 de la Constitución Política de los Estados Unidos Mexicanos, el control difuso que realizan los jueces ordinarios, en el ámbito de sus competencias, constituye una herramienta en su labor de decir el derecho conforme a la Carta Magna, facultad que se entiende en el sentido de que el órgano judicial puede ejercerla $e x$ officio, esto es, en razón de su función jurisdiccional y sin que medie petición de alguna de las partes.

\section{Vi. Presupuestos para ejercer el control difuso}

Ahora bien, no obstante que la Suprema Corte de Justicia de la Nación, como se hizo referencia en párrafos que anteceden, haya hecho la interpretación del artículo 133 constitucional para que los jueces puedan ejercerla ex officio, ahora toca explicar, la forma en que ese propio órgano jurisdiccional ha delimitado cómo debe llevarse a cabo el control difuso de convencionalidad y/o constitucionalidad.

En ese sentido, estableció en el criterio "PASOS A SEGUIR EN EL CONTROL DE CONSTITUGIONALIDAD Y CONVENCIONALIDAD EX OFFICIO EN MATERIA DE DEREGHOS HUMANOS", ${ }^{33}$ un sistema de control que se debe llevar a cabo en tres pasos. En el primero los jueces deben llevar a cabo una interpretación conforme en sentido amplio, es decir, de acuerdo a lo que establece el artículo $1^{\circ}$ constitucional. En segundo lugar, procederá a realizar una interpretación conforme en sentido estricto, consistente en que los jueces ante varios sentidos en los que la norma en cuestión puede ser interpretada, deberán

32 Guerrero Rodríguez, Marcelo, "Limitación al Poder Judicial de la Federación...", cit., pendiente de publicación.

33 Tesis P. LXIX/2011(9a.), Semanario Judicial de la Federación y su Gaceta, Décima Época, libro III, diciembre de 2011, t. 1, p. 552. 
elegir aquel que hace a la ley, acorde con los derechos humanos. Por último -tercero-, si la interpretación en sentido estricto no diera resultado, deberán, sin más remedio, inaplicar la norma en cuestión, lo que sostuvo el alto tribunal del país, no afecta o rompe con la lógica de los principios de división de poderes y de federalismo, sino que fortalece el papel de los jueces al ser el último recurso para asegurar la primacía y aplicación efectiva de los derechos humanos establecidos en la Constitución y en los tratados internacionales de los cuales el Estado Mexicano es parte.

Asimismo, la Suprema Corte de Justicia de la Nación ha delimitado que aun cuando el control difuso de constitucionalidad - connotación que incluye el control de convencionalidad- que ejercen los órganos jurisdiccionales en la modalidad ex officio no se encuentre limitado a las manifestaciones o actos de las partes ya que se sustenta en el principio iura novit curia - el juez conoce el derecho-, ${ }^{34}$ ello no implica que deba ejercerse siempre, pues existen presupuestos formales y materiales de admisibilidad y procedencia que deben tenerse en cuenta, como son, entre otros:

1. Que el juzgador sea competente legalmente para resolver el procedimiento o proceso en el que vaya a contrastar una norma.

2. Que si es a petición de parte, proporcionen los elementos mínimos para su estudio, es decir, señalar claramente cuál es el derecho humano o garantía que se estima infringido, la norma general a contrastar y el agravio que le produce, pues de otra forma, el juzgador no está obligado a emprender un estudio de los derechos humanos o preceptos constitucionales o convencionales que de manera genérica se invoquen.

34 Franco Cuervo, Juan José, "Iura novit curia vs. el test de argumentación mínima exigida por el juez o tribunal de amparo para la eficacia de los conceptos de violación o agravios", Revista del Instituto de la Fudicatura Federal, México, 2016, Núm. 42, p. 293, <https://www.ijf.cjf.gob.mx//Sitio2016/include/sections/ revista/42/13\%20Juan $\% 20 J o s \% \mathrm{C} 3 \%$ A9\%20Franco.pdf $>$, consultada el 23 de mayo de 2018 . 
3. Que debe existir aplicación expresa o implícita de la norma, aunque en ciertos casos también puede ejercitarse respecto de normas que, bien sea expresa o implícitamente, deban emplearse para resolver alguna cuestión del procedimiento en el que se actúa.

4. Que la existencia de un perjuicio en quien solicita el control difuso, o bien irrogarlo a cualquiera de las partes cuando se realiza oficiosamente.

5. Que no exista cosa juzgada respecto del tema a dilucidar en el juicio, porque si el órgano jurisdiccional ya emitió alguna resolución al respecto, incluso si ya realizó el control difuso y estimó que la norma es constitucional, no puede efectuarlo de nueva cuenta, máxime si algún órgano superior dejó firme esa decisión.

6. Que no exista jurisprudencia obligatoria emitida por el Poder Judicial de la Federación sobre la constitucionalidad de la norma, porque de existir, dicho criterio debe respetarse y subsistir.

7. Que no existan criterios vinculantes respecto de la convencionalidad de la norma general, ya que conforme a los criterios emitidos por la Suprema Corte de Justicia de la Nación, los emitidos por la Corte Interamericana de Derechos Humanos son vinculantes para todos los órganos jurisdiccionales del Estado Mexicano.

\section{vil. Conclusiones}

El control difuso de la constitucionalidad si bien es verdad no es un tema novedoso ni tampoco una nueva institución que se prevea en nuestra Constitución, tampoco podemos decir que no sea una cuestión interesante que deje de apasionar al público constitucionalista, pues sigue siendo debate en nuestro país si los órganos jurisdiccionales ordinarios -locales- deben ejercerlo como lo han venido haciendo los órganos de control constitucional -federales- habida cuenta que la facultad de inaplicar una norma, no debe ser a capricho del juzgador, sino que se debe llevar a cabo por expertos mediante un estudio metodológico y riguroso de la Constitución para 
considerarse un verdadero medio efectivo de control constitucional que a través del mismo se tenga la certeza de que cuando la norma general se encuentra en contravención a la Constitución o tratados internacionales que hayan sido suscritos y ratificados por el estado mexicano, prevalezcan los derechos humanos para garantizar al gobernado a través del mismo la protección efectiva de sus derechos.

Ahora, no obstante que los juzgadores ordinarios no pueden declarar la inconstitucionalidad de una ley, eso no los exime de llevar a cabo el control difuso de constitucionalidad como se los ordena el artículo 133 constitucional, ya que deben, en todo momento inaplicar la ley o normas secundarias que se encuentren en contravención a la norma fundamental del país, pues como lo dijo el maestro Burgoa, con ello no se está declarando expresamente su inconstitucionalidad sino que por un acto selectivo, ese juzgador opta por ceñir su conducta decisoria o ejecutiva a los mandatos constitucionales, absteniéndose de observar las normas secundarias que se le oponen. ${ }^{35}$

En ese sentido, es inconcuso que todos los operados del derecho, ya sean locales o federales, conforme a lo dispuesto en el multicitado artículo 133 constitucional, tienen la obligación de aplicar la Constitución por encima de cualquier ley que se le oponga, ya sea a petición de parte o de manera oficiosa, la cual debe llevar a cabo mediante una metodología básica y universal para arribar a la inaplicación de una norma contraria a la Constitución.

Asimismo, ese control no significa que siempre y sin excepción, los operadores jurídicos deban hacerlo, pues su ejercicio depende de la violación a los derechos humanos que pueda observar al momento de aplicar normas de derechos humanos, aun cuando no sean jueces de control constitucional y no exista una solicitud expresa de las partes.

35 Burgoa, Ignacio, El juicio de amparo, 40ª . ed., México, Porrúa, 2004, p. 158. 
Por tanto se puede afirmar que si bien es verdad existen procesos especiales para combatir los actos de autoridad contra aquellos que no son acordes con la Constitución, como el juicio de amparo, las controversias constitucionales y las acciones de inconstitucionalidad, también es cierto que el control difuso es un medio eficaz de control constitucional que permite y obliga a todos los jueces mexicanos a verificar si las normas, actos o resoluciones que emitan las autoridades se encuentran acordes a los derechos humanos y garantías que se prevén en la Constitución Política de los Estados Unidos Mexicanos y tratados internacionales, para que de no ser así, inapliquen a favor del gobernado las normas que hayan servido de base a esos actos, por lo que se concluir que no existe pretexto fundado o límite establecido para que todos los jueces del estado mexicano ejerzan esa facultad como una simple actividad de protección de derechos humanos en beneficio del gobernado; de ahí que se pueda sostener que dicho instrumento es un medio eficaz de control constitucional para salvaguardar los derechos humanos.

\section{Bibliografía}

Angulo Jасово, Luis Fernando, "El control difuso de convencionalidad en México", Revista del Instituto de la fudicatura Federal, México, 2013, Núm. 35, <https://www.ijf.cjf.gob.mx/Sitio2016/include/sections/revista/rev35_C.html>, consultada el 23 de mayo de 2018.

Becerra Ramírez, José de Jesús, "El camino hacia el control difuso de constitucionalidad en México: la convencionalidad", Revista el Cotidiano, México, 2013, Núm. 180, julio-agosto, <http://www.elcotidianoenlinea.com.mx/pdf/18003.pdf>, consultada el 23 de mayo de 2018 . 
Burgon, Ignacio, El juicio de amparo, 40ª . ed., México, Porrúa, 2004.

Caso Radilla Pacheco vs. México, sentencia de 23 de noviembre de 2009, Excepciones, Preliminares, Fondo, Reparaciones y Costas, Corte Interamericana de Derechos Humanos, <http:/ / www.ordenjuridico. gob.mx/JurInt/STCIDHM4.pdf>, consultada el 23 de mayo de 2018.

Franco Cuervo, Juan José, "Iura novit curia vs. el test de argumentación mínima exigida por el juez o tribunal de amparo para la eficacia de los conceptos de violación o agravios", Revista del Instituto de la Judicatura Federal, México, 2016, Núm. 42, <https://www.ijf.cjf. gob.mx//Sitio2016/include/sections/revista/42/13\%20Juan\%20 Jos\%C3\%A9\%20Franco.pdf>, consultada el 23 de mayo de 2018.

Guerrero Rodríguez, Marcelo, "Contradicción 293/2011. Inobservancia del principio pro persona", Revista del Instituto de la Fudicatura Federal, México, 2014, Núm. 36, enero, <https://www.ijf.cjf.gob. $\mathrm{mx} /$ publicaciones/revista/36/Marcelo\%20Guerrero\%20Rodr\%C3\%ADguez.pdf $>$, consultada el 23 de mayo de 2018, Núm 26, marzo-septiembre <http://letrasjurídicas.cuci.udg.mx/index.php/ letrasjurídicas/issue/view/228/showToc > consultda el 16 de noviembre de 2018

, Marcelo, "Limitación al Poder Judicial de la Federación del control de regularidad constitucional ex officio. Análisis del amparo directo en revisión 1046/2012", Letras Jurídicas, Revista Electrónica de Derecho del Centro Universitario de la Ciénega, México, 2018.

Mancilla Castro, Roberto Gustavo, "El principio de progresividad en el ordenamiento constitucional mexicano", Cuestiones Constitucionales. Revista Mexicana de Derecho Constitucional. México, UNAM, 2015, No. 33, julio-diciembre, <https://revistas.juridicas.unam.mx/index. $\mathrm{php} /$ cuestiones-constitucionales/article/view/6098/8039>, consultada el 23 de mayo de 2018. 
Márquez Martínez, Laura, Control difuso desde una perspectiva de derecho de acceso a la justicia, México, Suprema Corte de Justicia de la Nación, Comisión Organizadora del Poder Judicial para los festejos del Centenario de la Constitución Política de los Estados Unidos Mexicanos, 2017.

Rojas Caballero, Ariel Alberto, Los derechos humanos en México, México, Porrúa, 2012.

- Ariel Alberto, El control difuso y la recepción del control de convencionalidad en materia de derechos humanos en México, México, Porrúa, 2015.

Samaniego Santamaría, Luis Gerardo, "Control Difuso de constitucionalidad-convencionalidad. Evolución jurisprudencial a cien años de la constitución mexicana de 1917", en Ferrer Mac-Gregor, Eduardo y Flores Panoja, Rogelio (coord.), La constitución y sus garantías. A 100 años de la constitución de Querétaro de 1917. Memoria del XI encuentro Iberoamericano y VIII congreso mexicano de derecho procesal constitucional, México, UNAM, Instituto de Investigaciones Jurídicas, Instituto de Estudios Constitucionales de Querétaro, 2017, < https://archivos. juridicas.unam.mx/www/bjv/libros/10/4633/38.pdf>, consultada el 23 de mayo de 2018.

\section{LEGISLACIÓN}

Constitución Política de los Estados Unidos Mexicanos.

Diario Oficial de la Federación, 18 de enero de 1934,pp. 206-208, <http:/ / www.dof.gob.mx/nota_to_imagen_fs.php?cod_diario=191181\&pa gina $=3 \&$ seccion $=0>$, consultada el 23 de mayo de 2018 .

Diario Oficial de la Federación, 29 de enero de 2016, p. 25, <http://www. dof.gob.mx/nota_to_imagen_fs.php?.cod_diario $=268141 \&$ pagina $=$ $25 \&$ seccion $=0>$, consultada el 23 de mayo de 2018 .

Semanario Judicial de la Federación. 